\title{
Evaluation of the revitalization capacity of the historic building as an example of interdisciplinary diagnostics
}

\author{
Wojciech Terlikowski ${ }^{1{ }^{*}}$ \\ ${ }^{1}$ Warsaw University of Technology, ul. Kaczyńskiego 16, 00-637 Warsaw, Poland
}

\begin{abstract}
The revitalization process is an interdisciplinary process that combines many fields of economy and science. It is a set of urban planning, architectural and construction, economic, business, pro-social and pro-environment actions, which purpose is to lead the area out of a crisis situation. This is often done by restoring to the revitalized area its former utility function or creating a new one. In case of buildings, especially historic ones, located in the revitalized area, a key element of revitalization is their rehabilitation. The successful revitalization process requires adequate interdisciplinary diagnosis, taking into account not only the technical issues relating to the technical condition of the building, but also beyond technical issues arising from the principles of sustainable development. The revitalization capacity of the historic building is a set of features, properties and states defining the building, in terms of its construction, form, function, location, environmental, social and health values, defining opportunities and economic viability of planned revitalization, including all aspects of revitalization, also principles of sustainable development. The article discusses the methodologies for evaluation of the revitalization capacity of a historic building, on the example of interdisciplinary diagnostics of specific historic buildings located in Warsaw.
\end{abstract}

\section{Introduction}

Rehabilitation of historic buildings, usually understood as technical activities, is more and more often a part of revitalization, which is a broader and more complex process. This process is no longer a strictly technical one but requires the cooperation of experts in many fields of engineering, science, architecture, sociology and economy.

The revitalization is defined as a complex, interdisciplinary process of spatial, technical, architectural and urban changes, which are associated with social and economic change, undertaken in the public interest. The purpose of these activities is bringing the area out of a crisis situation by restoring its former functions or creating new ones and evolving conditions for its further development. The crisis means a series of destructive processes

\footnotetext{
* Corresponding author: w.terlikowski@il.pw.edu.pl
} 
affecting the space, buildings, technical devices, societies and economies that degrade the area.

Up to recent, the term revitalization was not used in the context of individual buildings, and referred only to the area where the building is possibly located. It should be noted that the concept of revitalization is constantly evolving and we can now talk about revitalization of buildings. In such case it is necessary to associate this process not only with technical and engineering activities, such as renovation or rehabilitation of structures, architectural forms or installations. It have to be considered in an interdisciplinary way, achieving the goals set in the definition of revitalization, by understanding a building as an integral part of the area. The aim of this article is to present the specificity of diagnostic activities related to revitalized historic buildings, as interdisciplinary research, taking into account the principles of sustainable development [1]. The significant element of such approach could be an assessment of the revitalization capacity of a building, which methodology is presented in the article.

\section{Concept of sustainable building diagnostics and building revitalization capacity}

In the process of revitalization of the areas where the historic buildings are located, the revitalization of these buildings is essential [2]. Historic buildings and other buildings in the crisis areas are usually important elements of this area, which forms its value and revitalization potential $[3,4]$. Very often, the improvement of the technical condition of these buildings is a basic technical activity necessary to make the efficient and effective revitalization of the whole area around the building [5].

Revitalization of a building, especially a historical one, is a complicated and complex investment process [3]. It is noticeable at the design stage as well as during construction. Taking into account all aspects of the interdisciplinary nature of revitalization including economic, social or cultural effects, force the need for a simple algorithm for assessing the initial cost-effectiveness and revitalization efficiency of the investment process. Such an algorithm has to consider the specific conditions of a building that could potentially be revitalized. There are numerous expert systems that can help and provide necessary solutions regarding structural aspects and energy efficiency [6] but there are no simple diagnostic tools in engineering and investment practice to simplify a preliminary assessment of whether a particular historic building is suitable for technical and nontechnical revitalization. Prior to commencing a revitalization process, frequently the investor does not have sufficient knowledge to rationalize the investment decision taking into account all aspects of revitalization. The revitalization capacity of a historic building may be then used, which is a form of extended, interdisciplinary diagnostics of a building. Using traditional approach to structural diagnostics, treatment of historical buildings do not exceed technical issues and limits to a construction diagnostics [7-9].

The revitalization capacity of a building (including the historic one) is a set of features, properties and states of the building, in the aspects of structure, form, function, location, environmental, social and health values, that specify possibility and the economic viability of the planned revitalization. Evaluation of a revitalization capacity of a building takes into account all aspects of revitalization including the principles of sustainable development [3]. The value of the revitalization capacity of a historic building can be specified by the formula (1), which is given in percentage points.

$$
Z_{\text {rew }}=\frac{\sum\left(O_{i} \cdot g_{i}\right) \cdot 100}{\sum\left(O_{i, \max } \cdot g_{i}\right)}
$$


where: $\mathrm{O}_{i}-$ evaluation of $\mathrm{i}$-aspect, $\mathrm{g}_{\mathrm{i}}-$ weight of $\mathrm{i}$-aspect of evaluation, $\mathrm{O}_{\mathrm{i}, \max }-$ maximum evaluation of $i$-aspect.

Assessment of revitalization capacity covers the issues arising from the principles of sustainable development in the construction industry, makes the scope of diagnostic research of the historic building significantly broader. The principles of sustainable development in the construction industry [1], show the close linkage of economics, society and the environment, should be present in every revitalization process. This results directly from the definition of both concepts. Sustainable development identifies a development process that strives to fully meet the diverse needs of the present generation and does not alter in any way the potential for future generations, giving them at least the same opportunities as to modern ones. This applies to well-thought-out economic, technical, economic and social activities, including the proper use of the environment, in a way that does not degrade or irreversible changes it, and all economic activities contributing to the misallocation of goods, resulting in a deeper economic differentiation of communities and societies, unequal economic growth or living standards. The emergence and abandonment of crisis areas - degraded in a technical, material and environmental sense, negatively impacting on social behavior, causing social and economic problems, is inconsistent with the idea of sustainable development. Revitalization is defined as complex, interdisciplinary action, involving spatial, technical, urban planning, aimed at deriving the area from a crisis situation. This is accomplished by restoring old functions or creating new ones and evolving conditions for its further development.

Parts of the revitalization activities are rehabilitation, modernization, adaptation of buildings located in crisis area which technical condition could directly or indirectly cause its occurrence. The technical and engineering activities on buildings, apart from the broader context, which incorporate interdisciplinary actions affecting the environment and social issues, cannot be considered as a revitalization. These activities become revitalization when they contribute to the emergence of a crisis area, improve the social situation, help to solve the social problems, positively affect the environment and the local community, for example through integration with the environment, natural stimulation of local entrepreneurship or cultural development. Although these behaviours do not appear to be directly related to construction activities, the appropriate investment process of the building revitalization project can influence the above mentioned issues, for example, proper choice of the function of the building or its part, adaptation of the building to new usage, selection of appropriate design solutions, technology and materials, including those that can stimulate the development of local entrepreneurship, for example in the field of small and medium enterprises. Sustainable diagnosis of historic buildings is an interdisciplinary activity that goes beyond building and technical issues. An interdisciplinary, balanced diagnostic approach is presented in Fig. 1 [10].

The assessment of the building's revitalization capacity gives a thorough knowledge not only about the technical and materials value but also about the intangible value. It is often a valuable added value, often overlooked in the engineer's diagnostic work. It should be noted that it is crucial in the case of historic buildings. It significantly increases the value arising only from the technical state, which is often not great, due to the progress of the degradation process of the construction of historical buildings. Identification (or at least estimation) of the revitalization capacity of a historic building at the initial investment stage can help an investor to make the key investment decisions, paying attention to the difficulty of the planned investment and showing areas of potential profits and positive impacts. Correct assessment of the revitalization capacity is carried out by detailed SWOT analysis [11]. 


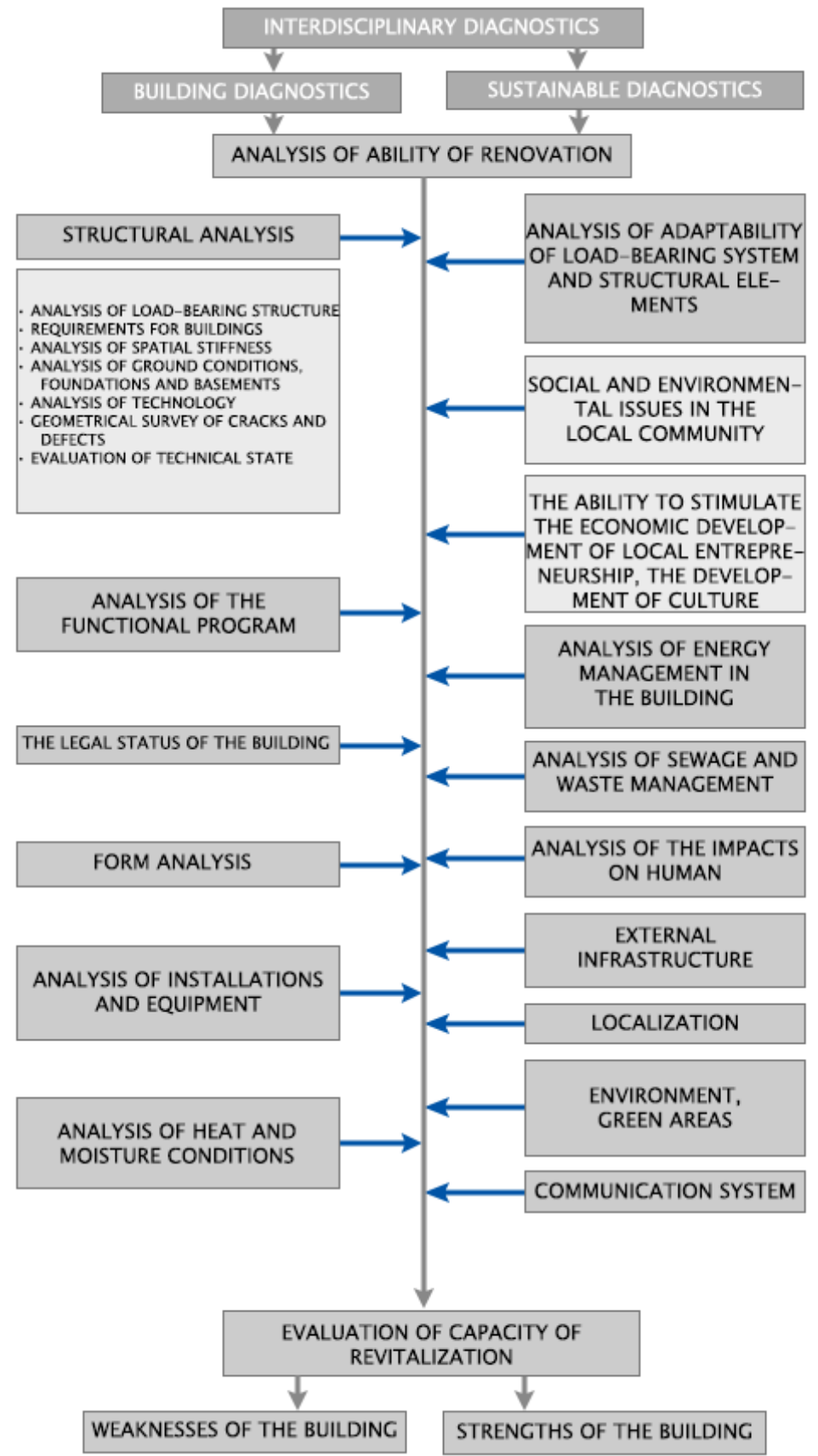

Fig. 1. An interdisciplinary, balanced diagnostic approach.

\section{Methodology of assessment the revitalization capacity}

The classical approach to the rehabilitation of historic buildings analyses the technical condition of the building - structure, architectural and construction elements, installations, the adaptation to the new functional and structural requirements and the current comfort of 
use. An analysis of the state of construction and usage safety combined with the new concept of building use, resulting from the revitalization process, answers the question whether and to what extent the building requires rescue, security, rehabilitation, rehabilitation, adaptation, modernization or repair actions. The concept of rehabilitation capacity $\left(Z_{\text {drew }}\right)$ of a revitalized historic building can be distinguished, which defines the capacity of a revitalized building for rehabilitation, combined with renovation, modernization and multi-faceted adaptation of the historic building to new technical and functional requirements. It is also necessary to determine the adaptability of the structural system, its components as well as the architectural and functional system to determine the value of rehabilitation capacity of a historic building. The value of the rehabilitation capacity of a historical building can be determined objectively and verifiably, by applying the rules of expertise, opinions and technical assessments that result from the construction practice. They are often based on generally accepted schemes and ratings that relate to commonly accepted criteria for wear of building elements. By determining the revitalization capacity of the historic building $\left(Z_{\text {drew }}\right)$ it can be stated that it is the sum of the rehabilitation capacity of the building $\left(\mathrm{Zd}_{\mathrm{reh}}\right.$ - based on classical diagnostics commonly used in construction practice) and the value of sustainability rate of the revitalization process $\left(\mathrm{W}_{\mathrm{zr}}\right)(2)$.

$$
Z d_{r e w}=Z d_{r e h}+W_{z r}
$$

Assessment of the revitalization capacity can be conducted at different levels. In a very general sense, the definition of revitalization capacity can be reduced to estimation of the value of many features that determine both the technical state of the building and the features of the sustainability approach. In general, the assessment may give an estimation of the revitalization capacity, showing the weaknesses and strengths of the revitalized building in the assessment process. By conducting advanced interdisciplinary diagnostics, depending on the degree of detail and expertise, revitalization can be more credible and give more objective results, not just general estimation. In the developed algorithm of assessment of the revitalization capacity of a historic building, about 100 characteristics and states were considered. They are organized in 8 main groups of issues: formal and legal, historical and cultural value, construction, human impact, external environment, energy efficiency, innovation, impact on the local community. This forms a framework for an interdisciplinary diagnostics. In the process of determining the revitalization capacity of a building, the characteristics and states are assessed by specific assessments (for example 0 to 5 ) on the basis of supporting tables. Depending on the group of issues, for the numerical results specific weights are given assigned to each group. These weights are based on an analysis of the LEED and BREEAM sustainable building certification systems and the author's own experiences. The result of the analysis is a point value (percentage points), which represents the final evaluation of the revitalization capacity of the historic building (deficient revitalization not recommended, sufficient - revitalization difficult with problems, good revitalization recommended, very good - revitalization with high success rate) (Table 1). In addition to the score, relevant information from the analysis is provided.

In order to analyse all aspects of revitalization in more detailed manner, the partial factors of particular revitalization aspects $\left(\mathrm{W}_{\mathrm{i}}\right)$ are helpful. They give the value of the aggregate assessment of a particular aspect of revitalization in a form of a percentage, assuming a maximum aggregate rating (made up of maximum partial ratings) of $100 \%$.

The following partial factors of particular aspects of the building revitalization can be distinguished:

$\mathrm{W}_{1}$ - the legal and formal state factor,

$\mathrm{W}_{2}$ - the historical and cultural value factor, 
$\mathrm{W}_{3}$ - the structural aspects factor,

$\mathrm{W}_{4}$ - the impact on human factor,

$\mathrm{W}_{5}$ - the external environment factor,

$\mathrm{W}_{6}$ - the energy efficiency factor,

$\mathrm{W}_{7}$ - the possibility of innovative solutions factor,

$\mathrm{W}_{8}$ - the impact on the local community factor.

$\mathrm{W}_{3}$ and $\mathrm{W}_{6}$ rates are useful for analyzing the rehabilitation capacity of the building $\mathrm{Zd}_{\text {reh }}$ and other $\mathrm{W}_{1}, \mathrm{~W}_{2}, \mathrm{~W}_{4}, \mathrm{~W}_{5}, \mathrm{~W}_{7}, \mathrm{~W}_{8}$ for the analysis of value of sustainability $\mathrm{W}_{\mathrm{zr}}$.

The predicted degree of sustainability of the revitalization process $\left(\mathrm{S}_{\mathrm{zr}}\right)$ is also an important factor. This is the projected value of the sustainability of the revitalization process, referring to the maximum value that can be obtained potentially in the process.

$$
S_{z r}=\frac{Z d_{r e w}-Z d_{r e h}}{\sum g_{i} \cdot w_{i, \max }-g_{3} \cdot w_{3, \max }}
$$

where: $g_{i}-$ weight of $i$-th aspect of the evaluation, $w_{i, \max }-$ maximum value of $i$-th rating.

Within the methodology of assessing the revitalization capacity of a historic building authors developed the tables to estimate each aspect of the evaluation, based on expert guidelines, standards, regulations and principles used in building and interdisciplinary diagnostics.

Table 1. Card to assess the revitalization capacity of a historic building

\begin{tabular}{cccc}
\hline & & Evaluation of the revitalization capacity \\
\hline No. & Points & Evaluation & Description \\
\hline 1 & $0-40$ & Deficient & Revitalization not recommended \\
2 & $40-60$ & Sufficient & Revitalization difficult with problems \\
3 & $60-80$ & Good & Revitalization recommended \\
4 & $80-100$ & Very good & Revitalization with high success rate \\
\hline
\end{tabular}

\section{Examples of evaluation of revitalization capacity of selected historical tenements in Warsaw}

As a part of a research project conducted by the Division of Fundamentals of Building and Sustainable Development of the Faculty of Civil Engineering of the Warsaw University of Technology, 30 historic buildings located in Warsaw in crisis areas dedicated to revitalization were examined. The revitalization capacity of each building, the value of the individual assessment factors and the degree of sustainability of individual revitalization projects were assessed. For each building, specific research metrics have been created that include the most important results, including the value of the revitalization capacity, showing the percentages of all factors, the value of individual assessment factors, and the degree of sustainability of revitalization. The extract of metrics for one of the sample tenements subjected to the survey are shown in Fig. 2.

The results of the research show the potential strengths and weaknesses of the examined buildings. This is not only the technical and material value of the buildings, but also the intangible value creating the added value. The value of building sustainability shows the potential for each building, while the building's rehabilitation value its current state. 


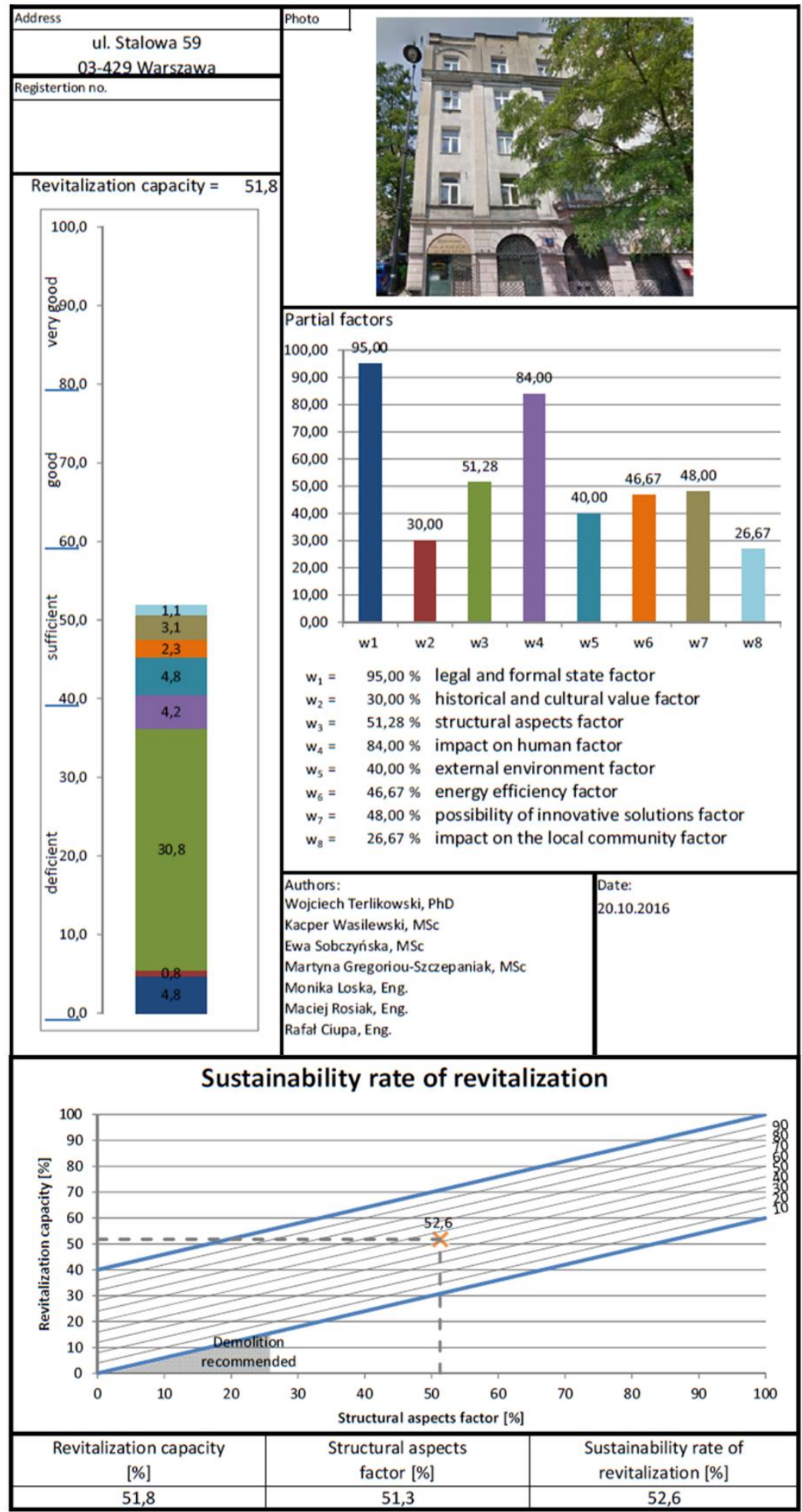

Fig. 2. Extract of the metrics of building revitalization capacity evaluation. 


\section{Conclusion}

Diagnostics of historic buildings should take into account the principles of sustainable development in civil engineering. This should be an interdisciplinary process, including not only the technical and structural aspects but also the non-technical ones arising from the revitalization process in which the rehabilitation of a historic building is an element. The assessment of the revitalization capacity including analysis of nearly 100 technical and nontechnical aspects, the designation of factors of this assessment, the sustainability rate of the building in the revitalization process, which can give full knowledge of the building's technical condition and potential opportunities resulting from its sustainability can be used. Research conducted by the Division of Fundamentals of Buildings and Sustainable Development of Warsaw University of Technology has shown that the analysis of the revitalization potential can contribute to the ordering of knowledge about revitalized historic buildings, assessing their value in terms of planned revitalization. This can be useful in the process of investment decision both by the investor, the designer and the building contractor. Assessment of the revitalization capacity of historic buildings may be useful for the creation of a comprehensive methodology for sustainable urban revitalization.

On the basis of the detailed assessment of the revitalization capacity of historic buildings, it is possible to determine the concepts of their revitalization, including necessary and possible revitalization actions including innovative ones in terms of technical aspects as well as pro-environmental and pro-social ones influences the local community and contributing to solving its problems. The possible revitalization actions are assessed on the basis of the particular features and factors. Based on these solutions, it is possible to identify modular, repeatable solutions depending on the specific boundary conditions related to the state of the examined building.

\section{References}

1. L. Czarnecki, M. Kaproń, Int. J. Soc. Mat. Eng. Resources 17(2), 99-106 (2010)

2. N. Doratli, S. Hoskara and M. Fasli, Cities 21(4), 329-348 (2004)

3. D. Dvornik Perhavec, N. Šuman, JCEEA 7(6), 712-722 (2013)

4. Great Britain. Parliament House of Commons. ODPM: Housing, Planning, Local Government and the Regions Committee, 2004. The role of historic buildings in urban regeneration : report, together with formal minutes, oral and written evidence, Conference publication: National government publication, English, London: Stationery Office.

5. E. Strzelecka, IJCEE 2, $661-668$ (2011)

6. A. Węglarz, P.G. Gilewski, MATEC Web Conf., 117,00176, (2017).

7. D. Diamantidis, M. Holicky, Innovative methods for the assessment of existing structures, Czech Technical University in Prague, ISBN: 978-80-01-05115-3 (2012)

8. ISO 13822:2010 Standard, Bases for design of structures - Assessment of existing structures

9. J. Hola , J. Bień, Ł.Sadowski and K.Schabowicz, Bulletin of the Polish Academy of Sciences Technical Sciences 63(1), 87-94 (2015)

10. W. Terlikowski, Mat. Bud. 490(5), 48-50 (2013)

11. W. Terlikowski, JCEEA, XXXIII(4/16), 531-538 (2016) 